\title{
Childhood body mass index and the risk of prostate cancer in adult men
}

\author{
J Aarestrup 1 , M Gamborg ${ }^{1}$, M B Cook ${ }^{2}$, T I A Sørensen ${ }^{1,3}$ and J L Baker ${ }^{\star}, 1,3$ \\ ${ }^{1}$ Institute of Preventive Medicine, Bispebjerg and Frederiksberg Hospital, The Capital Region, Nordre Fasanvej 5, Frederiksberg, \\ 2000 Copenhagen, Denmark; ${ }^{2}$ Division of Cancer Epidemiology and Genetics, National Cancer Institute, NIH, DHHS, 9609 \\ Medical Center Drive, Room 7-E106, MSC 9774, Bethesda, MD 20892-9774, USA and ${ }^{3}$ Novo Nordisk Foundation Center for Basic \\ Metabolic Research, Section on Metabolic Genetics, Faculty of Health and Medical Sciences, University of Copenhagen 1 , \\ 1. Floor, 2100 Copenhagen, Denmark
}

Background: Prostate cancer aetiology is poorly understood. It may have origins early in life; previously we found a positive association with childhood height. The effects of early life body mass index (BMl; $\mathrm{kg} \mathrm{m}^{-2}$ ) on prostate cancer remain equivocal. We investigated if childhood BMI, independently and adjusted for height, is positively associated with adult prostate cancer.

Methods: Subjects were a cohort of 125208 boys formed from the Copenhagen School Health Records Register, born 1930-1969 with height and weight measurements at 7-13 years. Cases were identified through linkage to the Danish Cancer Registry. Cox proportional hazards regressions were performed.

Results: Overall, 3355 men were diagnosed with prostate cancer. Body mass index during childhood was positively associated with adult prostate cancer. The hazard ratio of prostate cancer was 1.06 ( $95 \%$ confidence interval $(\mathrm{Cl})$ : $1.01-1.10)$ per $\mathrm{BMI}$ z-score at age 7, and 1.05 (95\% Cl: 1.01-1.10) per BMl z-score at age 13. Estimates were similar and significant at all other ages. However, adjustment for childhood height attenuated the associations at all but the youngest ages as most estimates became nonsignificant.

Conclusions: These results suggest that at most childhood ages, BMI does not confer an additional risk for prostate cancer beyond that of height.

Prostate cancer is the second most common cancer among men worldwide and it is most frequent in high-income countries (World Cancer Research Fund/American Institute for Cancer Research, 2007; Globocan, 2012). Despite affecting large numbers of men, the aetiology of the disease is poorly understood. Moreover, none of the well-established risk factors such as age, ethnicity or a family history of prostate cancer are modifiable. Other prostate cancer risk factors that have been identified include adult obesity and dietary components, each of which are potentially modifiable, as well as non-modifiable risk factors such as adult height, genetic polymorphisms and hormonal factors. The contributions of these factors to the aetiology of prostate cancer are, however, unclear (Gronberg, 2003; Hsing and Chokkalingam, 2006).
Adult anthropometry has been evaluated in relation to prostate cancer risk in several studies. Two meta-analyses have established that taller men have an increased risk of prostate cancer, however the effect sizes are modest (MacInnis and English, 2006;Zuccolo et al, 2008). Recently we found that tall boys, especially in late childhood, had an elevated risk of developing prostate cancer in adulthood (Cook et al, 2013). Additionally, several studies have found indications that adult obesity increases the risk of prostate cancer. However, the effect of greater adult body mass index (BMI; $\mathrm{kg} \mathrm{m}^{-2}$ ) on prostate cancer risk is relatively weak (ranging in magnitude from a 3 to $6 \%$ increased risk per $5 \mathrm{~kg} \mathrm{~m}^{-2}$; MacInnis and English, 2006; Renehan et al, 2008), although the effects appear to be stronger for aggressive and fatal prostate cancers (MacInnis and English, 2006;Discacciati et al, 2011; Discacciati et al, 2012).

*Correspondence: Dr JL Baker; E-mail: jennifer.lyn.baker@regionh.dk

Received 31 January 2014; revised 9 April 2014; accepted 24 April 2014; published online 27 May 2014

(c) 2014 Cancer Research UK. All rights reserved 0007-0920/14 
As the growth of the prostate organ starts early in life, and the development of prostate cancer likely occurs over a long period before it manifests clinically, it is plausible that this process originates early in life (Freedland and Platz, 2007; Wilson, 2011). Consequently, childhood may represent an essential period where early exposures could affect prostate cancer risk later in life.

Excess weight during childhood has various adverse consequences for long-term health (Ahlgren et al, 2004; Baker et al, 2007; Reilly and Kelly, 2011). Only a few studies have, however, investigated if childhood body size is associated with the risk of prostate cancer in adulthood, and their findings are equivocal (Andersson et al, 1995; Ilic et al, 1996; Giovannucci et al, 1997; Hsing et al, 2000; Dal et al, 2004; Jeffreys et al, 2004; Robinson et al, 2005; Barba et al, 2008). The only cohort study using measured heights and weights did not find an effect of childhood BMI, but this study was limited by a low number of prostate cancer cases as well as a wide age range of the included boys (Jeffreys et al, 2004). The remaining studies relied on a mid-life recall of childhood weight (Andersson et al, 1995; Ilic et al, 1996) or body size (Giovannucci et al, 1997; Hsing et al, 2000; Dal et al, 2004; Robinson et al, 2005; Barba et al, 2008), which might have resulted in exposure misclassification bias that usually results in attenuation of effects towards the null.

We investigated whether a larger BMI in childhood, independent of and adjusted for height, as well as longitudinal changes in BMI during childhood were associated with an increased risk of prostate cancer in adulthood in a large Danish population-based cohort of men. In addition, to examine whether changes in diagnostic procedures over time and the stage of the cancer affected these associations, we conducted additional analyses exploring the effects of the introduction of prostate-specific antigen (PSA) testing and the Tumour, Node, Metastasis (TNM) stage of the neoplasm.

\section{MATERIALS AND METHODS}

Cohort. This cohort study is based on data from the Copenhagen School Health Records Register, which contains computerised information on 372636 children. Virtually all school children born from 1930 to 1989 and attending private or public schools in the municipality of Copenhagen underwent annual mandatory health examinations through 1983. Thereafter the exams occurred only at school entrance and exit, or more frequently if the child had special health requirements. Heights and weights were measured by trained school physicians and nurses (Baker et al, 2009).

Each child's BMI was calculated and transformed to a z-score based on an internal age- and sex-specific reference chosen from a period when the prevalence of obesity was low and stable (Baker et al, 2007). The z-scores were computed using the Lamda, Median, Sigma (LMS) method (Cole and Green, 1992) as it accounts for skewness in distributions. Height measurements were transformed to z-scores based upon internal sex-, age- and birth cohort-specific references (5-year intervals), and they were also computed using the LMS method. Height references were specific for birth cohorts to account for secular increases in height. If a child had a measurement taken at the exact age, then this z-score was used. Otherwise $z$-scores were interpolated to the exact age if two measurements were available within a \pm 12 month period around the age of interest or extrapolated if only one was available within a \pm 12 month period.

The Danish Civil Registration System of vital statistics was established on 2 April 1968 and a unique identification (ID) number was assigned to every citizen who was alive or born thereafter (Pedersen, 2011). Children who attended school in 1968 or later had their ID number recorded on their health card, otherwise they were retrieved for children who left school prior to this time.
Using the ID number, prostate cancer status was obtained by linkage to the national Danish Cancer Registry (Gjerstorff, 2011). It is a population-based registry in which from 1943 onwards all incident malignant neoplasms are subject to notification; thus it has a very high degree of completeness. Further, the validity is high, exemplified by $89 \%$ of the tumours being morphologically verified (Storm et al, 1997; Gjerstorff, 2011). Prostate cancer was defined by International Classification of Diseases 10 code C61.9. Vital status was obtained by linkage to the vital statistics register (Pedersen, 2011).

Study population. To be eligible for this study, men had to have been born between 1930 and 1969, have an ID number (to enable follow-up) and be alive and living in Denmark at 40 years of age. Age at entry was set at age 40 years, as prostate cancer is not a disease of young men and no diagnoses of prostate cancer occurred below this age.

Of the initial 188360 boys constituting the total population of boys in the cohort, 153441 were born 1930-1969. Of these, 19794 were excluded due to not having an ID number, leaving 133647 men in the potentially eligible population. Additionally, men were excluded due to emigration $(N=2778)$, death $(N=3888)$ or loss to follow-up $(N=105)$ prior to 40 years of age resulting in 126876 eligible men. Of these, one man with a missing date of diagnosis, 1663 men without height and/or weight measurements at all ages between 7 and 13 years (those with missing values at each age from 7 to 13 years were excluded only from the specific analyses), one man with an outlying height measurement and three men with a BMI measurement outlier at all ages ( $\mathrm{z}$-score less than -4.5 or above 4.5) were excluded as well. Subjects were followed from 40 years of age until a diagnosis of prostate cancer, death, emigration, loss to follow-up or 31 December 2011; whichever came first.

The present study was approved by the Danish Data Protection Agency (Datatilsynet). According to Danish law, ethical approval is not required for purely register-based studies.

Statistical methods. Cox proportional hazards regression was used to examine the association between BMI z-scores at each age from 7 to 13 years and the risk of prostate cancer in adulthood calculated as hazard ratios (HRs). Further, we also investigated the association between longitudinal changes in BMI z-scores from ages 7 to 13 and the risk of prostate cancer. As BMI and height $\mathrm{z}$-scores are correlated in these boys $\left(r_{\mathrm{Age} 7}=0.17, r_{\mathrm{Agel} 13}=0.31\right)$, to examine the independent effect of BMI, all analyses were also performed with adjustment for childhood height. Further, we also investigated the association between height and prostate cancer, with and without adjustment for childhood BMI. Age at diagnosis was chosen as the underlying time scale. All analyses were stratified by 5 -year birth cohorts, thus allowing the baseline hazard to be different for each birth cohort.

The linearity of the associations was assessed by testing against a restricted cubic spline with 5 knots (Greenland, 1995). The proportional hazards assumption underlying the Cox models was investigated by keeping the association between BMI and prostate cancer risk constant within categories of age at diagnosis and testing if the association was the same in all categories. Owing to the large time period covered by the cohort, an interaction of birth cohort with the association between BMI and risk of prostate cancer was examined using 5-year intervals until 1950, while birth years beyond 1950 have been combined due to a limited number of cases. No deviations from linearity, violations of the proportional hazards assumption or birth cohort effects were detected (not shown).

As PSA testing has increased the detection rate of prostate cancer, particularly among latent prostate cancers, we conducted a sensitivity analyses based on the introduction of PSA testing. Prostate-specific antigen tests were officially recommended for use by the Danish Urological Society in November 1997 (Mukai et al, 2010), 
therefore we tested if the association between childhood BMI and prostate cancer differed between the pre-PSA (before 1 January 1998) and the post-PSA periods based on a likelihood ratio test. This analysis was restricted to men aged 40-68 years because the duration of follow-up before the introduction of the PSA tests did not allow for analyses at older ages.

It is possible that the association between BMI and prostate cancer risk depends on the severity of the disease. Thus, we stratified our analyses by cancer stage using the TNM classification system, which was included in the Danish Cancer Registry from 2004 onwards. In these analyses, 18155 men were censored due to emigration $(N=1017)$, death $(N=16354)$, loss to follow-up $(N=19)$ or being diagnosed with prostate cancer $(N=765)$ prior to 2004. Therefore, 107053 men were eligible for this analysis. Prostate cancers that were biopsied were classified as localised, metastatic or unknown (Supplementary Table 1). Only localised and metastatic forms were investigated.

\section{RESULTS}

At least one measurement of height and weight at a single age was available for 125208 boys. The median BMI values increased with age (Table 1). Thus, at age 7 the median BMI was $15.3 \mathrm{~kg} \mathrm{~m}^{-2}$, whereas at age 13 the median BMI was $17.7 \mathrm{~kg} \mathrm{~m}^{-2}$. In 2.7 million person-years of follow-up during a 42-year time-period, 3355 men were diagnosed with prostate cancer, with a median age at diagnosis of 66.5 years (ranging from 40.1 to 81.3 years).

We investigated if childhood BMI at each age from 7 to 13 years was associated with future risk of prostate cancer. At age 7, the HR of prostate cancer in adulthood was 1.06 (95\% confidence interval (CI): 1.01-1.10) per BMI z-score increase, and at 13 years the HR was 1.05 (95\% CI: 1.01-1.10) per BMI z-score increase (Figure 1 and Supplementary Table 2). The estimates were similar at the other ages and were significant at 8 years and borderline significant at ages 9 through 12 years. To put these effects into perspective, at age 7 years, $z$-scores of $-1,0$ and +1 correspond to BMI values of $14.3,15.4$ and $16.8 \mathrm{~kg} \mathrm{~m}^{-2}$, respectively, whereas at age 13 years the corresponding BMI values are $16.0,17.8$ and $20.3 \mathrm{~kg} \mathrm{~m}^{-2}$, respectively.

When adjusting for childhood height, the associations between childhood BMI and the risk of prostate cancer were attenuated (Figure 1 and Supplementary Table 2). Although the attenuation appeared to be smaller among the younger boys compared with the older boys, this may be a consequence of the increasing correlation between childhood BMI and height with age. Additionally, we investigated if adjustment for BMI affected the association between

\begin{tabular}{|c|c|c|}
\hline \multirow[b]{2}{*}{ Age (years) } & \multicolumn{2}{|c|}{$\mathrm{BMI}\left(\mathrm{kg} \mathrm{m}^{-2}\right)$} \\
\hline & $N$ & Median (5-95\%) \\
\hline 7 & 118083 & $15.3(13.7-17.4)$ \\
\hline 8 & 120375 & $15.6(14.0-18.0)$ \\
\hline 9 & 120179 & $16.0(14.2-18.7)$ \\
\hline 10 & 120071 & $16.3(14.4-19.5)$ \\
\hline 11 & 120085 & $16.7(14.7-20.3)$ \\
\hline 12 & 119559 & $17.2(15.0-21.1)$ \\
\hline 13 & 118393 & $17.7(15.3-21.8)$ \\
\hline
\end{tabular}

childhood height and prostate cancer risk. Results from these analyses showed that the effect of height is virtually independent of childhood BMI (Supplementary Table 3).

We also investigated if longitudinal changes in BMI z-scores between the ages of 7 and 13 were associated with prostate cancer risk. We did not find evidence for an association when adjusting for baseline BMI, $\left(\mathrm{HR}_{\Delta 7-13}\right.$ years $=1.02$ (95\% CI: 0.96-1.09)), nor when further adjusting for baseline height and changes in height between 7 and 13 years $\left(\mathrm{HR}_{\Delta 7-13 \text { years }}=0.95\right.$ (95\% CI: 0.89-1.02)).

Further, we conducted a sensitivity analyses stratified by preand post-PSA periods (men diagnosed before and after 1 January 1998) including 212 cases in the pre- and 1591 cases in the postPSA period (Table 2). Although there was a tendency for the associations between childhood BMI and prostate cancer risk to be considerably higher in the pre-PSA period, they were not significantly different from the associations in the post-PSA period (all $\left.P_{\text {interaction }}>0.10\right)$.

We also evaluated whether the association between childhood BMI and prostate cancer risk differed by the TNM stage of the cancer, where 1355 cases were classified as localised and 728 cases as metastatic, which all were diagnosed in the post-PSA era (Table 3). We found indications that a higher BMI in childhood is associated with an increased risk of localised prostate cancer, although when adjusting for childhood height the association became nonsignificant at all ages. There was no evidence that childhood BMI is associated with metastatic prostate cancer.

\section{DISCUSSION}

In this large population-based cohort study, although we found some evidence that a higher childhood BMI was associated with a modestly increased risk of prostate cancer in adulthood, the association attenuated after adjustment for childhood height. Nonetheless, as the association remained borderline significant among the youngest boys, there were indications that BMI in early childhood may be associated with prostate cancer risk independently of childhood height.

Few studies have investigated whether childhood body size is associated with the future risk of prostate cancer. Only one cohort study used measured heights and weights to assess the association between childhood BMI (at ages 2-14.9 years) and adult prostate cancer risk. The study found tentative evidence of a positive association (odds ratio per BMI z-score $=1.12$ (95\% CI: 0.72-1.72)) but was statistically limited because only 19 men were diagnosed with prostate cancer during follow-up (Jeffreys et al, 2004). In the other

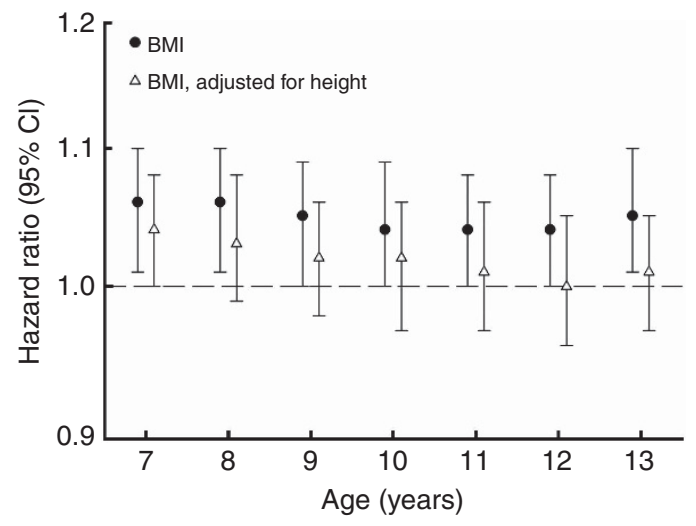

Figure 1. Hazard ratios and $95 \%$ confidence intervals for the risk of prostate cancer per 1-unit body mass index z-score in childhood (stratified by 5 -year birth cohorts allowing the baseline hazard to differ by birth cohort). 
Table 2. Hazard ratios and 95\% confidence intervals for the risk of prostate cancer at ages 40-68 years per 1-unit BMI z-score in childhood before and after the introduction of PSA tests in Denmark ${ }^{\mathrm{a}}$

\begin{tabular}{|c|c|c|c|c|c|c|c|c|c|c|c|c|}
\hline & \multicolumn{6}{|c|}{ Pre-PSA period } & \multicolumn{6}{|c|}{ Post-PSA period } \\
\hline $\begin{array}{l}\text { Age } \\
\text { (years) }\end{array}$ & $N$ & Cases & $\begin{array}{c}\text { Hazard } \\
\text { ratio }\end{array}$ & $\begin{array}{c}95 \% \\
\text { Confidence } \\
\text { interval }\end{array}$ & $\begin{array}{l}\text { Hazard } \\
\text { ratio }^{\mathrm{b}}\end{array}$ & $\begin{array}{c}95 \% \\
\text { Confidence } \\
\text { interval }\end{array}$ & $N$ & Cases & $\begin{array}{c}\text { Hazard } \\
\text { ratio }\end{array}$ & $\begin{array}{c}95 \% \\
\text { Confidence } \\
\text { interval }\end{array}$ & $\begin{array}{c}\text { Hazard } \\
\text { ratio }^{b}\end{array}$ & $\begin{array}{c}95 \% \\
\begin{array}{c}\text { Confidence } \\
\text { interval }\end{array}\end{array}$ \\
\hline 7 & 95049 & 189 & 1.18 & $1.00-1.39$ & 1.15 & $0.97-1.35$ & 107734 & 1522 & 1.06 & $1.00-1.12$ & 1.04 & $0.98-1.10$ \\
\hline 8 & 96790 & 197 & 1.13 & $0.95-1.34$ & 1.08 & $0.91-1.28$ & 109796 & 1540 & 1.07 & $1.01-1.13$ & 1.04 & $0.98-1.11$ \\
\hline 9 & 96727 & 197 & 1.13 & $0.95-1.34$ & 1.08 & $0.91-1.29$ & 109584 & 1536 & 1.05 & $0.99-1.11$ & 1.02 & $0.96-1.09$ \\
\hline 10 & 96621 & 197 & 1.15 & $0.97-1.37$ & 1.10 & $0.92-1.31$ & 109473 & 1534 & 1.06 & $1.00-1.12$ & 1.03 & $0.97-1.09$ \\
\hline 11 & 96547 & 198 & 1.20 & $1.01-1.43$ & 1.14 & $0.96-1.36$ & 109531 & 1538 & 1.05 & $0.99-1.11$ & 1.02 & $0.96-1.08$ \\
\hline 12 & 96095 & 194 & 1.22 & $1.02-1.45$ & 1.14 & $0.95-1.37$ & 109103 & 1534 & 1.06 & $1.00-1.12$ & 1.02 & $0.96-1.08$ \\
\hline 13 & 95030 & 186 & 1.26 & $1.06-1.51$ & 1.17 & $0.97-1.41$ & 108136 & 1525 & 1.08 & $1.02-1.14$ & 1.02 & $0.96-1.09$ \\
\hline
\end{tabular}

Table 3. Hazard ratios and $95 \%$ confidence intervals for the risk of prostate cancer per 1-unit BMI z-score in childhood according to TNM staging classification following subjects from 2004 onwards when TNM staging was introduced ${ }^{\text {a }}$

\begin{tabular}{|c|c|c|c|c|c|c|c|}
\hline & & & & \multicolumn{2}{|c|}{ BMI } & \multicolumn{2}{|c|}{ BMI adjusted for childhood height } \\
\hline Staging group & Age (years) & $N$ & Cases & Hazard ratio & $\begin{array}{l}95 \% \text { Confidence } \\
\text { interval }\end{array}$ & Hazard ratio & $\begin{array}{c}95 \% \text { Confidence } \\
\text { interval }\end{array}$ \\
\hline \multicolumn{8}{|l|}{ Localised } \\
\hline & $\begin{array}{r}7 \\
8 \\
9 \\
10 \\
11 \\
12 \\
13\end{array}$ & $\begin{array}{l}101401 \\
103325 \\
103136 \\
103059 \\
103150 \\
102792 \\
101903\end{array}$ & $\begin{array}{l}1277 \\
1298 \\
1295 \\
1291 \\
1287 \\
1275 \\
1256\end{array}$ & $\begin{array}{l}1.07 \\
1.07 \\
1.05 \\
1.06 \\
1.05 \\
1.05 \\
1.07\end{array}$ & $\begin{array}{l}1.01-1.14 \\
1.00-1.14 \\
0.99-1.12 \\
0.99-1.13 \\
0.98-1.12 \\
0.98-1.12 \\
1.00-1.14\end{array}$ & $\begin{array}{l}1.06 \\
1.05 \\
1.03 \\
1.04 \\
1.02 \\
1.02 \\
1.04\end{array}$ & $\begin{array}{l}0.99-1.13 \\
0.98-1.12 \\
0.96-1.10 \\
0.97-1.11 \\
0.96-1.09 \\
0.96-1.09 \\
0.97-1.11\end{array}$ \\
\hline \multicolumn{8}{|l|}{ Metastatic } \\
\hline & $\begin{array}{r}7 \\
8 \\
9 \\
10 \\
11 \\
12 \\
13\end{array}$ & $\begin{array}{l}101401 \\
103325 \\
103136 \\
103059 \\
103150 \\
102792 \\
101903\end{array}$ & $\begin{array}{l}677 \\
687 \\
695 \\
699 \\
698 \\
694 \\
680\end{array}$ & $\begin{array}{l}1.04 \\
1.04 \\
1.04 \\
1.02 \\
1.00 \\
0.99 \\
0.99\end{array}$ & $\begin{array}{l}0.95-1.13 \\
0.95-1.13 \\
0.95-1.13 \\
0.93-1.11 \\
0.91-1.10 \\
0.91-1.08 \\
0.91-1.08\end{array}$ & $\begin{array}{l}1.03 \\
1.02 \\
1.02 \\
1.00 \\
0.98 \\
0.96 \\
0.96\end{array}$ & $\begin{array}{l}0.94-1.12 \\
0.93-1.12 \\
0.93-1.12 \\
0.91-1.09 \\
0.89-1.07 \\
0.88-1.06 \\
0.88-1.06\end{array}$ \\
\hline
\end{tabular}

studies of childhood body size and prostate cancer risk, the evidence for an association is equivocal (Andersson et al, 1995; Ilic et al, 1996; Giovannucci et al, 1997; Hsing et al, 2000; Dal et al, 2004; Robinson et al, 2005; Barba et al, 2008). The inconsistency in the findings may result from limitations in using recalled childhood body size, which might introduce misclassifications attenuating potential associations.

It has been shown that adiposity, given by body fat percentage measured by DEXA, is positively associated with height in childhood (Metcalf et al, 2011). Similarly, we found BMI as a measure of childhood adiposity to be positively associated with childhood height. When we accounted for these associations by adjusting for childhood height, the association between BMI and prostate cancer decreased at all ages. Previously we reported that an increase in childhood height $\mathrm{z}$-score at each age from 7 to 13 years had a strong and positive association with future prostate cancer (Cook et al, 2013). Similar associations were found in the current analyses, which included an additional year of follow-up and 365 more cases compared to the previous study. When further adjusting for childhood BMI, the results were essentially unchanged (Supplementary Table 3). Taken together, these findings suggest that at most of these childhood ages, BMI does not confer an additional risk for prostate cancer beyond that of height. Only at age 7 years were there indications that BMI may be independently associated with prostate cancer risk. We are unable to compare our results with the few other studies on 
childhood BMI as they did not include estimates adjusted for childhood height.

We also investigated if longitudinal changes in BMI z-score from 7 to 13 years were associated with later prostate cancer risk. However, we did not find changes in BMI to be significantly related to prostate cancer risk. In our previous findings of childhood height we found that longitudinal changes in height from 7 to 13 years given height at age 7 years increased the risk of adult prostate cancer (Cook et al, 2013). Previous studies have not reported on changes in childhood BMI in relation to later prostate cancer risk, likely due to a lack of repeated measurements of childhood body size available at different ages.

Body size in childhood and adulthood are correlated, however the tracking of body size is generally moderate and varies in magnitude across studies (Sørensen and Sonne-Holm, 1988; Power et al, 1997; Singh et al, 2008). Nonetheless, we do not have available information on adult body size. If tracking of body size strongly mediated our findings, it would be expected that the association with prostate cancer would be stronger among the oldest children as body size in late childhood (i.e., age 13 years) is more proximal in time to adult body size, and thus more correlated than body size in early childhood (i.e., age 7 years). After adjustment for height, however, the strongest association was among the youngest children. Thus, tracking of body size across the life course is not likely to be the explanation for our findings.

Prostate cancer is a malignancy expected to be histologically present in the vast majority of men if living long enough (Haas et al, 2008), thus making the incidence partly dependent on the intensity of diagnostic procedures. The introduction and widespread use of PSA testing as a diagnostic tool of prostate cancer in the 1980-90s in the USA and Europe has increased the detection rate of latent prostate cancers (Welch and Albertsen, 2009; Neppl-Huber et al, 2012). We did not find significant differences in the associations of BMI with prostate cancer in the periods before and after the introduction of PSA. However, there was tentative evidence for a stronger association in the pre-PSA period, but the analyses were limited by the relatively small number of diagnosed prostate cancers in this period.

The association between adult BMI and prostate cancer differs depending on the aggressiveness of the cancer. Some studies have found indications of a moderate inverse association between BMI and localised prostate cancer, whereas others have shown positive associations. Body mass index has consistently been found to be positively associated with advanced prostate cancers (MacInnis and English, 2006; Discacciati et al, 2012). We found indications of a positive association between childhood BMI and localised prostate cancers. However, there was no evidence for a positive association with metastatic prostate cancer and this might reflect that the metastatic group is fairly heterogeneous and includes prostate cancers with different stages and spread. Two previous studies on recalled childhood body measures have assessed associations with prostate cancer stage. One study found indications of an inverse association between childhood body size at ages 5 and 10 years and advanced and metastatic prostate cancers in adult life (Giovannucci et al, 1997), while another study found indications of an inverse association between childhood body size at age 10 years and advanced prostate cancer (Robinson et al, 2005). In general, there is no overall congruence among studies how to define the different stages of prostate cancer. Further, staging might inadequately measure aggressiveness as it reflects the stage at the time of initial diagnosis and does not take potential progression into account.

A unique feature of our study is the population-based nature as well as its very large size due to the mandatory health examinations. Also, the follow-up of subjects was nearly complete, and due to a long follow-up period a considerable number of prostate cancer cases were diagnosed. Our study may be limited by the inability to classify prostate cancer cases by aggressiveness based on Gleason score as this is not electronically available. Men with a higher socioeconomic status have a higher risk of prostate cancer; however, this association has commonly been ascribed to higher rates of PSA testing among men of these groups (Gilligan, 2005). In Denmark there is equal access to universal and free health care, thereby making selection and detection bias less likely. As the included children did not belong to a selected group with a high socioeconomic status, the likelihood of this kind of selection bias is reduced in our study population.

In conclusion, we found evidence that a higher BMI in childhood is associated with an increased risk of prostate cancer in adult life, although adjustment for child height attenuated these associations at most ages except among the youngest boys, thus suggesting that BMI does not add a substantial risk for prostate cancer beyond that of height. Even though the magnitude of the adverse effect of excess childhood adiposity on prostate cancer risk is moderate, the findings contribute to our limited knowledge about risk factors for prostate cancer.

\section{ACKNOWLEDGEMENTS}

The research leading to these results has received funding from the European Research Council under the European Union's Seventh Framework Programme (FP/2007-2013)/ERC Grant Agreement no. 281418, childgrowth2cancer to JLB. MBC was supported by the Intramural Program of the National Cancer Institute, National Institutes of Health, Department of Health and Human Services, USA.

\section{CONFLICT OF INTEREST}

The authors declare no conflict of interest.

\section{REFERENCES}

World Cancer Research Fund/American Institute for Cancer Research Food, Nutrition, Physical Activity, and the Prevention of Cancer: a Global Perspective. AICR: Washington DC (2007) .

Globocan (2012) Estimated Cancer Incidence, Mortality and Prevalence Worldwide in 2012. International Agency on Cancer (IARC). World Health Organization (WHO). Accessed January 2014. http:// globocan.iarc.fr/2014.

Ahlgren M, Melbye M, Wohlfahrt J, Sørensen TIA (2004) Growth patterns and the risk of breast cancer in women. N Engl J Med 351(16): 1619-1626.

Andersson SO, Baron J, Wolk A, Lindgren C, Bergstrom R, Adami HO (1995) Early life risk factors for prostate cancer: a population-based case-control study in Sweden. Cancer Epidemiol Biomarkers Prev 4(3): 187-192.

Baker JL, Olsen LW, Andersen I, Pearson S, Hansen B, Sørensen TIA (2009) Cohort profile: the Copenhagen School Health Records Register. Int J Epidemiol 38(3): 656-662.

Baker JL, Olsen LW, Sørensen TIA (2007) Childhood body-mass index and the risk of coronary heart disease in adulthood. N Engl J Med 357(23): 2329-2337.

Barba M, Terrenato I, Schunemann HJ, Fuhrman B, Sperati F, Teter B, Gallucci M, D'Amato A, Muti P (2008) Indicators of sexual and somatic development and adolescent body size in relation to prostate cancer risk: results from a case-control study. Urology 72(1): 183-187.

Cole TJ, Green PJ (1992) Smoothing reference centile curves: the LMS method and penalized likelihood. Stat Med 11(10): 1305-1319.

Cook MB, Gamborg M, Aarestrup J, Sørensen TIA, Baker JL (2013) Childhood height and birth weight in relation to future prostate cancer risk: a cohort study based on the Copenhagen School Health Records Register. Cancer Epidemiol Biomarkers Prev 22(12): 2232-2240.

Dal ML, Zucchetto A, La VC, Montella M, Conti E, Canzonieri V, Talamini R, Tavani A, Negri E, Garbeglio A, Franceschi S (2004) Prostate cancer and 
body size at different ages: an Italian multicentre case-control study. Br J Cancer 90(11): 2176-2180.

Discacciati A, Orsini N, Andersson SO, Andren O, Johansson JE, Wolk A (2011) Body mass index in early and middle-late adulthood and risk of localised, advanced and fatal prostate cancer: a population-based prospective study. Br J Cancer 105(7): 1061-1068.

Discacciati A, Orsini N, Wolk A (2012) Body mass index and incidence of localized and advanced prostate cancer-a dose-response meta-analysis of prospective studies. Ann Oncol 23(7): 1665-1671.

Freedland SJ, Platz EA (2007) Obesity and prostate cancer: making sense out of apparently conflicting data. Epidemiol Rev 29: 88-97.

Gilligan T (2005) Social disparities and prostate cancer: mapping the gaps in our knowledge. Cancer Causes Control 16(1): 45-53.

Giovannucci E, Rimm EB, Stampfer MJ, Colditz GA, Willett WC (1997) Height, body weight, and risk of prostate cancer. Cancer Epidemiol Biomarkers Prev 6(8): 557-563.

Gjerstorff ML (2011) The Danish Cancer Registry. Scand J Public Health 39(7 Suppl): $42-45$.

Greenland S (1995) Dose-response and trend analysis in epidemiology: alternatives to categorical analysis. Epidemiology 6(4): 356-365.

Gronberg H (2003) Prostate cancer epidemiology. Lancet 361(9360): 859-864.

Haas GP, Delongchamps N, Brawley OW, Wang CY, de la Roza G (2008) The worldwide epidemiology of prostate cancer: perspectives from autopsy studies. Can J Urol 15(1): 3866-3871.

Hsing AW, Chokkalingam AP (2006) Prostate cancer epidemiology. Front Biosci 11: 1388-1413.

Hsing AW, Deng J, Sesterhenn IA, Mostofi FK, Stanczyk FZ, Benichou J, Xie T, Gao YT (2000) Body size and prostate cancer: a population-based casecontrol study in China. Cancer Epidemiol Biomarkers Prev 9(12): 1335-1341.

Ilic M, Vlajinac H, Marinkovic J (1996) Case-control study of risk factors for prostate cancer. Br J Cancer 74(10): 1682-1686.

Jeffreys M, Smith GD, Martin RM, Frankel S, Gunnell D (2004) Childhood body mass index and later cancer risk: a 50-year follow-up of the Boyd Orr study. Int J Cancer 112(2): 348-351.

MacInnis RJ, English DR (2006) Body size and composition and prostate cancer risk: systematic review and meta-regression analysis. Cancer Causes Control 17(8): 989-1003.

Metcalf BS, Hosking J, Fremeaux AE, Jeffery AN, Voss LD, Wilkin TJ (2011) BMI was right all along: taller children really are fatter (implications of making childhood BMI independent of height) EarlyBird 48. Int J Obes (Lond) 35(4): 541-547.

Mukai TO, Bro F, Pedersen KV, Vedsted P (2010) [Use of prostate-specific antigen testing]. Ugeskr Laeger 172(9): 696-700.
Neppl-Huber C, Zappa M, Coebergh JW, Rapiti E, Rachtan J, Holleczek B, Rosso S, Aareleid T, Brenner H, Gondos A (2012) Changes in incidence, survival and mortality of prostate cancer in Europe and the United States in the PSA era: additional diagnoses and avoided deaths. Ann Oncol 23(5): $1325-1334$.

Pedersen CB (2011) The Danish Civil Registration System. Scand J Public Health 39(7 Suppl): 22-25.

Power C, Lake JK, Cole TJ (1997) Body mass index and height from childhood to adulthood in the 1958 British born cohort. Am J Clin Nutr 66(5): 1094-1101.

Reilly JJ, Kelly J (2011) Long-term impact of overweight and obesity in childhood and adolescence on morbidity and premature mortality in adulthood: systematic review. Int J Obes (Lond) 35(7): 891-898.

Renehan AG, Tyson M, Egger M, Heller RF, Zwahlen M (2008) Body-mass index and incidence of cancer: a systematic review and meta-analysis of prospective observational studies. Lancet 371(9612): 569-578.

Robinson WR, Stevens J, Gammon MD, John EM (2005) Obesity before age 30 years and risk of advanced prostate cancer. Am J Epidemiol 161(12): $1107-1114$.

Singh AS, Mulder C, Twisk JW, van MW, Chinapaw MJ (2008) Tracking of childhood overweight into adulthood: a systematic review of the literature. Obes Rev 9(5): 474-488.

Sørensen TIA, Sonne-Holm S (1988) Risk in childhood of development of severe adult obesity: retrospective, population-based case-cohort study. Am J Epidemiol 127(1): 104-113.

Storm HH, Michelsen EV, Clemmensen IH, Pihl J (1997) The Danish Cancer Registry-history, content, quality and use. Dan Med Bull 44(5): 535-539.

Welch HG, Albertsen PC (2009) Prostate cancer diagnosis and treatment after the introduction of prostate-specific antigen screening: 1986-2005. J Natl Cancer Inst 101(19): 1325-1329.

Wilson JD (2011) The critical role of androgens in prostate development. Endocrinol Metab Clin North Am 40(3): 577-590.

Zuccolo L, Harris R, Gunnell D, Oliver S, Lane JA, Davis M, Donovan J, Neal D, Hamdy F, Beynon R, Savovic J, Martin RM (2008) Height and prostate cancer risk: a large nested case-control study (ProtecT) and meta-analysis. Cancer Epidemiol Biomarkers Prev 17(9): 2325-2336.

This work is published under the standard license to publish agreement. After 12 months the work will become freely available and the license terms will switch to a Creative Commons AttributionNonCommercial-Share Alike 3.0 Unported License.

Supplementary Information accompanies this paper on British Journal of Cancer website (http://www.nature.com/bjc) 